\title{
MODELLING THE HIDDEN ECONOMY AND THE TAX-GAP IN NEW ZEALAND
}

\author{
David E. A. Giles*
}

Revised, February 1999

\section{Department of Economics, University of Victoria \\ P.O. Box 1700, STN CSC, Victoria, B.C. \\ Canada, V8W 3P5}

(FAX: (250) 721-6214; Voice: (250) 721-8540; e-mail: dgiles@uvic.ca )

\author{
Proposed Running Head: New Zealand Hidden Economy \\ Keywords: $\quad$ Underground Economy; Latent Variables; Tax Avoidance; Tax \\ JEL Classification(s): $\quad$ C32; C51; E32; E41 \\ Evasion; Tax-Gap
}

\begin{abstract}
* I am grateful to Patrick Caragata, for initiating and supporting this research, and for his many contributions which have greatly improved this paper. Earlier versions were discussed at Workshops on the Health of the New Zealand Tax System, Wellington, 1995. I would like to thank Daniel Aldersley, Lief Bluck, Johannah Branson, Phil Briggs, Linda DeBenedictis, Erwin Diewert, Johannah Dods, Paul Dunmore, Michael Dunn, Ed Feige, Judith Giles, Chris Gillion, Anna Heiller, Knox Lovell, Ewen McCann, Michael O'Connor, Gerald Scully, John Small, Adolf Stroombergen, and Ken White for their many comments, suggestions, and assistance with data. The insightful comments of two referees led to a significant improvement of this paper, including the addition of Appendix II. The content this paper is the responsibility of the author, and should not be attributed to Inland Revenue New Zealand, which financed this study. The author's related papers on the hidden economy and tax evasion are available in Adobe pdf format on the internet at http://web.uvic.ca/econ/economet_he.html.
\end{abstract}




\begin{abstract}
This paper develops and estimates a structural, latent variable, model for the hidden economy in New Zealand, and a separate currency-demand model. The estimated latent variable model is used to generate an historical time-series index of hidden economic activity, which is calibrated via the information from the currency-demand model. Special attention is paid to data non-stationarity, and to diagnostic testing. Over the period 1968 to 1994, the size of the hidden economy is found to vary between $6.8 \%$ and $11.3 \%$ of measured GDP. This, in turn, implies that the total tax-gap is of the order of $6.4 \%$ to $10.2 \%$ of total tax liability in that country. Of course, not all of this foregone revenue would be recoverable, as not all of the activity in the underground economy is responsive to changes in taxation or other policies.
\end{abstract}




\section{INTRODUCTION}

Foregone tax revenue resulting from the underground economy is a major, and apparently growing, problem. We describe a modelling methodology which yields a time-series of the underground economy for New Zealand, from which a series of the "tax-gap" can be obtained. there have been no previous attempts to obtain such measures for New Zealand previously, but this is a topical issue in view of the current political debate on taxation policy and taxation compliance in that country.

The hidden economy and tax-gap have sizeable budgetary implications, and implications for taxation incidence and income distribution. For instance, if a principal cause of growth in the hidden economy is an actual, or perceived, increase over time in the tax burden, then an increase in (average or marginal) tax rates may reduce revenue and worsen the budget deficit. Similarly, if there is a significant hidden component to economic activity, then many economic indicators will be measured with error. Finally, there are political and social implications - a flourishing informal sector may reflect dissatisfaction, on the part of the electorate, with the degree of regulation of their activities.

There is an extensive literature on the measurement of the hidden economy, and section II discusses the major methods that have been used to address this issue. Our own econometric methodology is described in section III; data issues are discussed in section IV; and sections V and VI discuss the formulation and estimation of our models. section VII provides estimated time-paths for the hidden economy and the tax-gap in New Zealand, and our conclusions are summarized in section VIII.

\section{MEASURING THE HIDDEN ECONOMY}

The evidence on the actual size of the hidden economy is very mixed. Frey and Weck-Hanneman (1984) report that for seventeen OECD countries in 1978, the size of the underground economy (relative to GNP) varied from $4.1 \%$ for Japan, through $8.0 \%$ for the UK and $8.3 \%$ for the USA, to $13.2 \%$ in the case of Sweden, and with Canada at the sample mean of 8.8\%. In more recent work, Schneider (1997) found that the average OECD figure had risen to about 15\% of GDP by 1994, with Canada still close to this international average. The latter figure can be compared with the 5\% to $7 \%$ 
of GDP that Mirus and Smith (1994) estimate for Canada in 1976, rising to almost 15\% in 1990. Spiro (1994) estimates the Canadian underground economy at between 8\% and 11\% of GDP in 1993.

Other studies summarised by Aigner et al. (1988) report figures for the USA in 1978 which range from 4\% (Park (1979)) to 33\% (Feige (1982)) of GNP. On the other hand, evidence for the USA in 1970 yields a range, for this ratio, from 2.6\% (Tanzi (1983)) to 11\% (Schneider and Pommerehne (1985)). Bhattacharyya (1990) estimates the hidden economy for the UK to be $3.8 \%$ of GNP in 1960, with a peak of $11.1 \%$ in early 1976, and averaging around 8\% during 1984; while a British Inland Revenue analysis reported by Chote (1995) suggests that the hidden economy comprises $6 \%$ to $8 \%$ of GDP. The available evidence is varied and imprecise, but the results of our study are consistent with the more robust of the above numbers. There are several surveys of the literature on measuring the hidden economy, including those of Blades (1982), Boeschoten and Fase (1984), Carter (1984), Frey and Pommerehne (1982, 1984), Gaertner and Wenig (1985), Kirchgaessner (1984), Weck (1983), and Tedds (1998).

As well as providing information about the range of the international estimates, these surveys discuss the different techniques (and their strengths and weaknesses) that have been used by various authors. One criticism of most of these approaches is that they focus on one cause of underground economic activity, and one indicator. In contrast, Frey and Weck-Hannemann (1984), Aigner et al. (1988), and Tedds (1998) use "latent variable" structural modelling to measure the size of the hidden economy. The (unobservable) latent variable here is the extent of underground activity, perhaps expressed as a percentage of measured real GDP. The MIMIC ("Multiple Indicators, Multiple Causes") model of Zellner (1970), Goldberger (1972), Jöreskog and Goldberger (1975), and others allows for several "indicator" variables and several "causal" variables in forming structural relationships to "explain" the latent variable. This latent variable/MIMIC model approach forms the basis for our own analysis here. 


\section{A MODELLING METHODOLOGY}

The MIMIC model is a variant of the LISREL ("Linear Interdependent Structural Relationships") models, of Jöreskog and Sörbom (1993a,b) and others. A MIMIC model uses observable data on a range of "causal" variables, and a range of data on observable "indicator" variables, to "predict" the values for one or more unobserable ("latent") varaibles. This type of model yields only an time-series index for the latent variables - in our case there is just one such variable, namely the size of the underground economy relative to the size of measured GDP. Accordingly, some sort of extraneous information is needed to calibrate the index so that we can then construct a cardinal time-path of the underground economy. Once the underground activity is measured, the effective tax rate (i.e., the ratio of tax revenue to GDP) can be used to obtain an estimate of the size of the "tax-gap", and to address other policy issues.

We calibrate our hidden economy index via the estimation of a particular currency demand equation. Our currency-demand equation differs from the interesting model proposed by Bhattacharyya (1990), also in the context of underground activity. We allow for different velocities of circulation in the "hidden" and "recorded" sectors; explicitly "explain" hidden activity; and avoid a functional approximation in his approach. We allow for the non-stationarity of our time-series data, which he, and others, do not. Interestingly, our results imply a long-run average value for the "size" of the hidden economy that is almost identical to that obtained by using Bhattacharyya's approach in an earlier version of our work (Giles (1995, 1997a)), as is discussed briefly in Appendix II.

In our model, measured (nominal) currency demand is :

$$
\mathrm{M}_{\mathrm{t}}=\beta_{0}^{\prime} \quad \mathrm{Y}_{\mathrm{Rt} 1}^{\beta} \mathrm{Y}_{\mathrm{Ht} 2}^{\beta} \mathrm{R}_{\mathrm{t} 3}^{\beta} \mathrm{P}_{\mathrm{t} 4}^{\beta},
$$

where $\mathrm{Y}_{\mathrm{Rt}}$ and $\mathrm{Y}_{\mathrm{Ht}}$ are "recorded" and "hidden" real output or income, $\mathrm{R}_{\mathrm{t}}$ is a short-term interest rate variable, and $\mathrm{P}_{\mathrm{t}}$ is the price level. The unobservable ratio of "hidden" to "recorded" activity is taken to be a function of variables such as the rate of growth in measured output; the inflation rate and the

change in the latter; variables measuring the extent of the tax burden; and one to allow for the 
introduction of the Goods and Services Tax (GST) in October 1986. The latter is included because Inland Revenue Department (IRD) records suggest that the introduction of this tax in 1986 (together with the simultaneous abolition of sales taxes and dramatic changes to the personal and sales tax scales) had a negative impact on unrecorded activity, especially among the self-employed. The inflation rate is included to allow for the upward "creep" of taxpayers through the tax brackets that it causes, and the associated incentive for tax-payers to engage in unreported activities. A more pervasive effect of inflation is that, as it tends to be uneven across sectors, it alters income distribution, and this may induce disrespect for tax law. The change in the rate of inflation is included in equation (2) below because such variability adds to uncertainty, and strengthens the incentive to enter the hidden economy as a means of risk or cost reduction. So, we have:

$$
\left(\mathrm{Y}_{\mathrm{Ht}} / \mathrm{Y}_{\mathrm{Rt}}\right)=\alpha_{1}+\alpha_{2} \mathrm{GST}_{\mathrm{t}}+\alpha_{3} \Delta \log \mathrm{Y}_{\mathrm{Rt}}+\alpha_{4} \Delta \log \mathrm{P}_{\mathrm{t}}+\alpha_{5} \Delta\left(\Delta \log \mathrm{P}_{\mathrm{t}}\right)
$$

Solving (2) for $\mathrm{Y}_{\mathrm{Ht}}$, substituting in (1), taking (natural) logarithms, adding an error term and dummy variables to allow for deterministic seasonality, and for the introduction of "EFTPOS" ("Electronic Fund Transfer at Point of Sale"), bank debit card electronic retail transactions in lieu of cash in 1987.2:

$$
\begin{gathered}
\mathrm{m}_{\mathrm{t}}=\beta_{0}+\left(\beta_{1}+\beta_{2}\right) \mathrm{y}_{\mathrm{Rt}}+\beta_{2} \log \left[\alpha_{1}+\alpha_{2} \mathrm{GST}_{\mathrm{t}}+\alpha_{3} \Delta \mathrm{gdp} \mathrm{p}_{\mathrm{t}}+\alpha_{4} \Delta \mathrm{p}_{\mathrm{t}}+\alpha_{5} \Delta\left(\Delta \mathrm{p}_{\mathrm{t}}\right)\right] \\
+\beta_{3} \mathrm{r}_{\mathrm{t}}+\beta_{4} \mathrm{p}_{\mathrm{t}}+\delta_{1} \mathrm{~S}_{1 \mathrm{t}}+\delta_{2} \mathrm{~S}_{2 \mathrm{t}}+\delta_{3} \mathrm{~S}_{3 \mathrm{t}}+\delta_{4} \mathrm{DEFT}+\epsilon_{\mathrm{t}}
\end{gathered}
$$

where $\beta_{0}=\log \left(\beta_{0}{ }^{\prime}\right)$, lower case symbol denote natural logarithms of the variables, $S_{\mathrm{i}}$ is the $i^{\prime}$ th seasonal dummy, and DEFT is the EFTPOS dummy. (We also considered adding a variable for the value of EFTPOS transactions as a regressor, without success. A "dynamic" version of the model, incorporating a lagged value of the dependent variable as an additional regressor was also considered, as were the inclusion of various "tax burden" variables in equation (2). None of these refinements produced satisfactory results

In Table 1 below we also report on specifications of (1) which include $\left(\mathrm{P}_{t} / \mathrm{P}_{\mathrm{t}-1}\right),\left(\mathrm{P}_{\mathrm{t}} / \mathrm{P}_{\mathrm{t}-4}\right)$, or their lagged values, as regressors with a coefficient denoted $\beta_{5}$. Estimates of the $\alpha_{i}$ 's and of $\gamma$ can be used 
with (2) to measure $\left(\mathrm{Y}_{\mathrm{Ht}} / \mathrm{Y}_{\mathrm{Rt}}\right)$ at each point in the sample. These values are of less interest than those obtained from the MIMIC model, as they are based rather narrowly on a single-equation model, but they provide a useful cross-check on orders of magnitude. The estimate of $\alpha_{1}$ in Table 1 is also especially important in its own right as it measures the "long-run average" value for this ratio, and is used for the calibration of the MIMIC model.

Our MIMIC model of the hidden economy is formulated mathematically as follows: $\eta$ is the scalar (unobservable) "latent" variable (the size of the hidden economy); $\mathbf{y}^{\prime}=\left(\mathrm{y}_{1}, \mathrm{y}_{2}, \ldots ., \mathrm{y}_{\mathrm{p}}\right)$ is a vector of "indicators for $\eta ; \mathbf{x}^{\prime}=\left(\mathrm{x}_{1}, \mathrm{x}_{2}, \ldots ., \mathrm{x}_{\mathrm{q}}\right)$ is a vector of "causes" of $\eta ; \lambda$ and $\gamma$ are $(\mathrm{p} \times 1)$ and $(\mathrm{q} \times 1)$ vectors of parameters; and $\epsilon$ and $\zeta$ are $(\mathrm{p} \times 1)$ and scalar random errors. It is assumed that $\zeta$ and all of the elements of $\epsilon$ are Normal and mutually uncorrelated, with $\operatorname{Var} .(\zeta)=\psi$, and $\operatorname{Cov} .(\epsilon)=\Theta_{\epsilon}$. The MIMIC model is :

$$
\begin{gathered}
\mathbf{y}=\lambda \eta+\epsilon \\
\eta=\gamma^{\prime} \mathbf{x}+\zeta .
\end{gathered}
$$

Substituting (5) into (4), the MIMIC model can also be viewed as a multivariate regression model,

$$
\mathbf{y}=\Pi \mathbf{x}+\mathbf{z}
$$

where $\Pi=\lambda \gamma^{\prime}, \mathbf{z}=\lambda \zeta+\epsilon$, and $\operatorname{Cov} .(\mathbf{z})=\lambda \lambda^{\prime} \psi+\Theta_{\epsilon}$.

The p-equation model in (6) has a regressor matrix of rank one, and the error covariance matrix is also constrained. Accordingly, we cannot obtain cardinal estimates of all of the parameters. Only certain "estimable functions" of the parameters can be identified, so we can estimate the relative magnitudes of the parameters, but not their levels. Thus, the estimation of (4) and (5) requires a normalization for (4), which is generally achieved by constraining one element of $\lambda$ to a pre-assigned value. As both $\mathbf{y}$ and $\mathbf{x}$ are observable data vectors, the multi-equation model in (6) can then be estimated by conventional (restricted) Maximum Likelihood Estimation - in our case we have used 
the LISREL package (Jöreskog and Sörbom (1993a,b)) to obtain consistent and asymptotically efficient estimates of the elements of $\Pi$, and hence of $\lambda$ and $\gamma$.

Given an estimate of the $\gamma$ vector, and setting the error term $\zeta$ to its mean value of zero, equation (5) enables us to "predict" ordinal values for $\eta$ (which in our case is the hidden economy) at each sample point. Then, if we have a specific value for $\eta$ at some sample point, obtained form some other source, we can convert the within-sample predictions for $\eta$ into a cardinal series. We use the "average" value for $\left(\mathrm{Y}_{\mathrm{Ht}} / \mathrm{Y}_{\mathrm{Rt}}\right)$ from our estimated currency demand equation (i.e., our estimate of $\alpha_{1}$ ) to calibrate our time-series for the hidden economy by setting the latter to this value in 1981 .

\section{DATA ISSUES}

The variables are defined in Appendix I. Given the limitations of quarterly New Zealand time-series data, our MIMIC models have been estimated with annual data, for 1968 to 1994, but some experimentation with simple quarterly MIMIC models yielded strikingly similar results. Our currency demand model has been estimated with quarterly data for 1975.1 1994.4. Considerable attention has been paid to testing for stationarity and cointegration, and this appears to be the first application of a MIMIC model which addresses these issues.

The logarithms or levels of the series, as appropriate, have been tested for unit roots at the appropriate frequencies. Complete details of these unit root test results are given by Giles (1995, 1997a). Following Dickey and Pantula (1987), we test I(3) against I(2). If we reject I(3) we then test $\mathrm{I}(2)$ against $\mathrm{I}(1)$. Then we test $\mathrm{I}(1)$ against $\mathrm{I}(0)$, as appropriate. We have used the "augmented" Dickey-Fuller (ADF) test (e.g., Said and Dickey (1984)) to test for unit roots at the zero frequency. The quarterly data are not seasonally adjusted, and in this case we include a drift and seasonal dummy variables in the ADF regression and choose an augmentation level of at least three. This is based on the evidence provided by Ghysels et al. (1994). The lower limit of $\mathrm{p}=3$ was never binding, as can be seen from Table 1. The dummy variables $\left(S_{1 t}, S_{2 t}\right.$, and $\left.S_{3 t}\right)$ allow for deterministic seasonality in the data, and in this case the ADF regression is always fitted with a "drift" term. Dods and Giles (1995) show that for samples of our size a preferred method involves choosing this number 
so that the autocorrelation and partial autocorrelation functions for the residuals of the ADF regression are "clean", and this is the procedure followed here. To determine if a time-trend should also be included in the ADF regression, we follow the Dolado et al. (1990) sequential testing strategy. The series PUBEMP exhibits a major structural break in its trend from 1988, and as this will distort the ADF "t-tests" in favour of not rejecting a unit root, Perron's (1989) modified test has been used in this case.

With the quarterly data we also allow for stochastic seasonality, and test for unit roots at the zero, $\pi$, and ( $\pi / 2)$ frequencies, following Hylleberg et al. (1990) (or HEGY hereafter) and Ghysels et al. (1994). We have determined the augmentation levels in the HEGY regressions in the same way as for the ADF tests. Following the recommendations of Ghysels et al. (1994), we include a trend, drift, and seasonal dummy variables in the HEGY regressions.

\section{ESTIMATING THE CURRENCY DEMAND MODEL}

Our currency demand model is given in equation (3), and it contains several non-stationary variables. The stationarity of the regressor in (3) whose coefficient is $\beta_{2}$ is unclear - this term is both non-linear and unobservable; but $\mathrm{p}_{\mathrm{t}}$ and $\mathrm{m}_{\mathrm{t}}$ are both $\mathrm{I}(2)$, and $\mathrm{y}_{\mathrm{t}}$ and $\mathrm{r}_{\mathrm{t}}$ are $\mathrm{I}(1)$, so we have an "unbalanced regression". We cannot simply "filter" the series according to their orders of integration, as this generates many negative observations, making the estimation of the model impossible. Estimating the model without filtering the data would result in a "spurious regression" (Granger and Newbold (1974)). One possibility is to exploit any cointegration among the variables, and estimate (3) directly as a long-run cointegrating relationship, resulting in valid asymptotic inferences. Testing for cointegration is complicated, here, given the mixture of I(1) and I(2) variables, the non-linear model, and the possibility of seasonal cointegration. Given these problems, a simple but somewhat indirect cointegration testing strategy has been followed. The HEGY tests indicate that the only potential for cointegration is at the zero frequency, but this is rejected when standard Engle-Granger tests are applied. We then apply Haldrup's (1994) tests for cointegration involving I(2) data, using withinsample predictions for the series, $\log \left[\alpha_{1}+\alpha_{2} \mathrm{GST}_{\mathrm{t}}+\alpha_{3} \Delta \operatorname{gdp}_{\mathrm{t}}+\alpha_{4} \Delta \mathrm{p}_{\mathrm{t}}+\alpha_{5} \Delta\left(\Delta \mathrm{p}_{\mathrm{t}}\right)\right]$. The null of no cointegration is again easily rejected, providing reasonable justification treating our estimated 
"unbalanced" regressions as long-run equilibrium relationships. More complete details of this aspect of the modelling work are given by Giles (1997a).

The results of estimating the currency demand model, by Maximum Likelihood, using the SHAZAM (1993) package, over the period 1975.1 to 1994.4, appear in Table 3 for our preferred specification, together with some alternative specifications, including several in which the inflation rate enters the basic equation (1), with a coefficient denoted $\beta_{5}$. (In Models 3 and 5 the regressor associated with $\beta_{5}$ is the current quarterly rate of inflation; in Model 2 it is this rate lagged one period; and in Model 4 it is the lagged annual inflation rate.) These results illustrate the robustness of our estimate of the long-run average ratio of "hidden" to "measured" output, $\alpha_{1}$. A range of conventional diagnostic tests for the preferred specification appear in Table 4.

The within-sample averages of the "predicted" $\left(\mathrm{Y}_{\mathrm{Ht}} / \mathrm{Y}_{\mathrm{Rt}}\right)$ ratio, from equation (2), range from 8.4\% to $8.7 \%$ across the models. In "Model 1" this estimated ratio varies from $5.5 \%$ to $10.8 \%$ over the sample, and these values may be compared with the data in Figure 1 below. The estimates of $\alpha_{1}$, which represent long-run average values for $\left(\mathrm{Y}_{\mathrm{Ht}} / \mathrm{Y}_{\mathrm{Rt}}\right)$ generally are very "sharp", and are consistent with the value arrived at from a different currency-demand model - a modification of that of Bhattacharyya (1990) - in Appendix II. The estimate of $\alpha_{1}$ is $8.9 \%$ for Model 1, and that the corresponding sample average of $\left(\mathrm{Y}_{\mathrm{Ht}} / \mathrm{Y}_{\mathrm{Rt}}\right)$ is $8.7 \%$, so we use $8.8 \%$ in 1981.4 , which is where the sample mean of the GDP series occurs, to calibrate our MIMIC models below by setting the "predicted" hidden economy series to this value in 1981.

The sample correlation between actual and "fitted" $\mathrm{m}_{\mathrm{t}}$ is 0.99 for all of the models in Table 3, and the estimated coefficients have the expected signs. As $\beta_{0}=\log \left(\beta_{0}{ }^{\prime}\right)$, its sign is ambiguous, even though we expect $\beta_{0}>0$. The anticipated sign of $\beta_{5}$ is also ambiguous: we might expect high inflation to lead to a reduction in the holding of nominal balances, including currency; or, as the estimated Models 2 to 4 are non-homogeneous in prices, a positive estimate of $\beta_{5}$ may reflect the effect of inflationary expectations. This is not an issue in the preferred Model 1. Although the significance of the individual parameter estimates is "mixed", many of the key parameters are precisely estimated. Testing the appropriate non-linear restrictions on the parameters with Wald tests, 
we reject income homogeneity, but cannot reject (short-run) price homogeneity at the $10 \%$ significance level, or lower in Model 1.

In Table 4, GOF is the goodness-of-fit test for normal errors, and JB is the corresponding JarqueBera (1980) test statistic. There is no evidence of non-normal errors. RESET2, RESET3 and RESET4 are asymptotic versions of Ramsey's (1969) test for a mis-specified functional form and/or omitted variables, constructed as Wald tests and using powers of the predicted values of $\mathrm{m}_{\mathrm{t}}$. The RESET2 and RESET4 statistics are significant at the $2.5 \%$ level, but the latter is not significant at the $1 \%$ level. DeBenedictis and Giles (1998) show that the RESET test has extremely poor power, and is often a "biased" test. (That is, its power can fall below its significance level over part of the parameter space.) They propose an alternative test using a Fourier approximation, and show that it has excellent power. Their FRESET2, FRESET3 and FRESET 4 tests in Table 4 are asymptotically valid in the present context. FRESET2 is based on two sine terms plus two cosine terms, etc. The outcomes of these tests clearly support the this model's specification.

LM1 to LM4 are Lagrange Multiplier tests for serial independence against the respective alternatives of first, and general second, third and fourth order autoregressive (or moving average) errors. There is no evidence of serial correlation. $\mathrm{H} 1, \mathrm{H} 2$ and $\mathrm{H} 3$ are tests for heteroscedasticity based on regressing the recovered squared residuals from the non-linear regression on the fitted values, the square of the fitted value, and the logarithm of the square of the fitted values respectively. Although the various tests have only asymptotic justification here, given the non-linearity of the model, the results in Table 4 strongly support our preferred currency demand model, and its use as the basis for calibrating the predictions from our structural MIMIC model.

\section{ESTIMATING THE"MIMIC" MODEL OF THE HIDDEN ECONOMY}

Prior to the estimation of the MIMIC model by the LISREL package, all of the data have been filtered to make them stationary, according to the orders of integration in Table 2. For instance, $\log \mathrm{CPI}$ is second-differenced, $\log \mathrm{GDP}$ and UN are first-differenced, but PUBEMP and REGS are not differenced at all prior to the estimation of the model. The coefficient of the labour force 
participation rate "indicator" is constrained to unity, without loss of generality, in order to ensure the identification of the models, in view of the shortage of rank noted earlier in section III. The Maximum Likelihood estimates of the coefficients $(\gamma)$ of the "causal" variables $(\mathbf{x})$ in the structural equation for the hidden economy $(\eta)$ in equation (5) provide the basis for predicting $\eta$ (the size of the hidden economy) over the sample period. These estimates of the elements of $\gamma$ are obtained only up to a scale factor, and they are used as relative weights to obtain a time-series index for $\eta$. The actual (not differenced) values of the causal variables are used with the estimated elements of $\gamma$. This index is then scaled to take a value of $8.8 \%$ in 1981 , and this provides a series for the hidden economy, as a percentage of recorded real GDP.

Several MIMIC model specifications have been considered. Following earlier such studies for other countries, our "causal" variables allow for unemployment and income effects; the degree of economic regulation; the development of taxation legislation; the tax-bracket "creep" effect of inflation; and measures of the "tax burden". Up to three "indicator" variables are incorporated - the rate of growth in real GDP; the proportion of currency to M3; and the male labour force participation rate. As noted already, we have constrained the coefficient of the latter variable to unity to identify the models. Although Frey and Weck-Hanneman (1984) and Aigner et al. (1988) argue that this variable should be a negative indicator of the size of the hidden economy, in the New Zealand case it is clear from audit records and other evidence that most unrecorded economic activity is undertaken by agents who are also in the recorded workforce, suggesting a positive relationship. Indeed, we have found no models involving a negative coefficient for MPRT, and in which the signs of the various causal variable coefficients are all of the anticipated signs.

The implied series for the hidden economy are generally insensitive to the model specification. Representative results appear in Table 5. Model 1 is very sparsely specified, and Model 5 generates an implausible historical time-series for the hidden economy. It is included, however, to illustrate that the statistical significance of the individual variables may not be the most important issue. The overall "fit" of the model is also important, as is the economic "believability" of the model's implications. For reasons given below, Model 2 is our preferred specification. 
The results in Table 5 permit some interesting interpretations. Unlike the situation in a conventional regression model, because of the normalizations that have been introduced in the estimation of a MIMIC model the values of the estimated coefficients can be compared in relative terms. For instance, as we have normalized the coefficient of the male labour force participation rate (MPRT) variable to unity when identifying the model, the estimated coefficients on the "logGDP" indicator variable suggest not only a significant positive relationship between the size of the hidden economy and growth in measured GDP, but they also suggest that the effect of the hidden economy on the rate of growth in GDP is 1.2 to 2.8 times as great as its effect on the male labour force participation rate. The predicted positive effect of the hidden economy on the ratio of currency to M3 (i.e., CM3) is more stable (and quite significant) across the different versions of the model, being of the order of 0.75 times that of the effect of the hidden economy on the male labour force participation rate. These values have obvious implications regarding the relative merits of these "indicator" variables as reflections of movements in the unobservable underground economy in New Zealand.

Although the "causal" variables have the anticipated signs, many of them lack individual significance. Exceptions include the inflation rate and the (separate) ratios of corporate and "other" taxes to GDP in most of the models. An inspection of the coefficients of the causal variables is also revealing. For example, if we consider Model 2 (which we focus on below as a "preferred" specification), then the following emerges if we "distribute" the sum of the absolute coefficients across the various general types of causal factors: taxation effects (in terms of both the overall "burden" and the make-up of the tax-take) account for $52 \%$ of the causal effects; inflation accounts for $24 \%$; regulatory effects for $11 \%$; real personal income for $8 \%$; and the unemployment rate for $5 \%$. So, for example, the (positive) effects of an increase in inflation on the size of the underground economy are estimated to be roughly twice as important as the (positive) effects of an increase in the amount of regulation in the economy. This is not surprising when one takes into account the secondary effect of inflation whereby it induces "bracket-creep" with respect to the statutory tax schedule, and effectively increases the average marginal tax rate, ceteris paribus.

Other inferences are also interesting. For instance, the introduction of the GST (and the simultaneous dramatic reductions in direct taxes) in 1986 were roughly twice as important in reducing the size of 
the hidden economy as are reductions in the average tax rate for average tax payers. Similarly, the increase in the GST rate from $10 \%$ to $12.5 \%$ in mid-1989 took effect in conjunction with a halving of the land tax rate, and a very recent reduction of the corporate tax rate from $45 \%$ to $28 \%$ and a simplification of the personal tax schedule to a two-step system. These changes to the tax burden and tax-mix led to a reduction in the hidden economy, but the effect of these changes was only about $80 \%$ as important as the earlier such changes in 1986. Finally, we see increase in the unemployment rate lead to an increase in the size of the underground economy, and the associated impact is almost identical to the reduction in the underground economy that results from a tightening of taxation regulations.

The Chi Square statistics in Table 6 test the specifications of the MIMIC models against the alternative that the covariance matrix of the observed variables is unconstrained (see Jöreskog and Sörbom (1993a, pp.121-122)). Small values reflect a good "fit" of the models. The other statistics relate to criteria for measuring the overall performance of a MIMIC model. (See Jöreskog and Sörbom (1993a, Chap. 4).) Small values of Akaike's (1974) Information Criterion (AIC); of Bozdogan's (1987) CAIC measure; of the single-sample Cross-Validation Index (ECVI); and of the Root Mean Square Residual (RMR) measure favour the model. Large values of the Adjusted Goodness of Fit Index (AGFI), and the Parsimony Goodness of Fit Index (PGFI), reflect a good model fit. These measures should not be compared across models with different sets of indicator variables (and hence different likelihood functions).

The results in Table 6 are satisfactory. The various measures favour Models 2 and 4 over Model 3, so we focus on the more comprehensive Model 2, this being least prone to mis-specification bias.. We have used the estimated " $\Pi$ matrix" to construct conventional regression residuals series, these being the difference between the fitted and actual values for these "dependent" variables at each sample point for the GDP, MPRT and CM3 equations, scaled to have a zero sample mean in each case. We have then tested them for normality and serial correlation, in Table 7 . The notation is as in Table 4, and the results further support Model 2. The use of these diagnostic tests must be treated cautiously in the context of a MIMIC model. While the tests will have asymptotic justification, our sample is quite small, and diagnostic testing in such models is largely unexplored in the literature, 
and certainly worthy of further attention in the future.

\section{THE HIDDEN ECONOMY AND THE TAX-GAP}

Figure 1 provides an annual time-series of the New Zealand hidden economy, as a percentage of real measured GDP. This series was generated by multiplying the causal variables' data, by their associated estimated coefficients (the elements of $\gamma$ in equation (5)) as shown for MIMIC Model 2 in Table 5. The hidden economy series was then scaled to match the long-run average figure of $8.8 \%$ in 1981 implied by our currency demand equation results discussed earlier. Corresponding hidden economy series based on the other MIMIC models are given by Giles (1995). Except when the series for the number of public sector employees (which has a major distortive break in its trend in 1988) is included as a "causal" variable, the time-paths are strikingly similar in their overall cyclical movement, and differ only slightly in terms of actual magnitudes. In all cases there is a pronounced downward shift in the relative size of the hidden economy immediately after the introduction of the GST, and the simultaneous reductions in the sales, personal and corporate tax rates in October 1986. Actual real hidden and measured GDP are presented as separate time-series over our sample in Figure 2.

The hidden economy follows the phases of the business cycle in New Zealand. Unrecorded economic activity increased from around $6.8 \%$ of measured real GDP in 1968 to a peak of $11.3 \%$ in 1987, then fell to $8.7 \%$ of GDP in 1992 before increasing to around $11.3 \%$ in 1994. There is a secondary effect in the cyclical decline at the time of the increase in the GST rate from 10\% to $12.5 \%$ on 1 July 1989. Clearly, underground economic activity in New Zealand is positively tied to the business cycle and to the tax burden. Giles and Caragata (1998) and Caragata and Giles (1998) provide simulation results for the responsiveness of the size of the hidden economy to changes in the tax burden and tax mix. The rapid rise in the size of the hidden economy in the early 1970's is consistent with the expansion in real output which took place at that time in New Zealand prior to the international oil price shocks. The cyclical movements during the mid-1970's to mid 1980's follow the (less pronounced) pattern in measured output; and the trough in 1992 (and subsequent expansion), is also associated with the general cyclical movements in the economy. The absolute size of the hidden 
economy exhibits greater volatility than does measured real output - the associated sample coefficients of variation are $25.9 \%$ and $15.0 \%$ respectively.

On the basis of these data, Giles (1997b) finds clear evidence of Granger causality from measured to hidden activity, and weak evidence of reverse causality. This poses a dilemma for policy-makers wishing to stimulate economic growth, but contain the "tax-gap". These data are also used by Giles (1997d, 1999) to test for asymmetries in the measured and hidden business cycles. No asymmetries are found, implying that fiscal and monetary policy changes that respond to the observed business cycle are likely to have consistent effects on the hidden cycle. Finally, Giles (1997c) finds strong evidence of Granger causality from tax-related prosecutions to the size of the hidden economy in New Zealand, suggesting that the compliance efforts of the IRD are pro-active, rather than reactive.

Unrecorded economic activity is untaxed, implying a shortfall between actual and potential tax revenue. The total "tax-gap" can be estimated by multiplying the hidden/measured GDP ratio by total tax revenue, and the associated results (as percentages of total tax liability or of nominal GDP) appear in Figure 3. (The tax-gap, as a percentage of total tax liability is a monotonic increasing function of the Hidden/measured GDP ratio, so the "shape" of the former graph in Figure 3 is identical to that of the latter in Figure 1.) The tax-gap ranged from $6.4 \%$ to $10.2 \%$ of total tax liability over the sample, representing NZ\$0.07Billion to NZ\$3.18Billion in foregone nominal revenue. This compares with IRS audit-based tax-gap estimates for the United States of the order of $19 \%, 18 \%$ and 17\% (of total tax liability) in 1985, 1988 and 1992 for individual tax-payers (Internal Revenue Service (1996)). Of course, this measure of the tax-gap has to be qualified, as it assumes that all hidden activity is taxable, and that the incidence of the existing tax structure would be the same within the hidden sector as it is within the currently measured sector of the economy. Some aspects of these issues are addressed by Caragata and Giles (1998) and Giles and Caragata (1998): they provide simulation evidence indicating that in the New Zealand context, about half of the tax-gap is responsive to fiscal instruments (on average over the cycle), the rest being hard-core criminal evasion. They also show that a shift in favour of indirect taxation, and away from direct personal income tax, can have a significant impact on hidden activity and the tax-gap. 


\section{CONCLUDING COMMENTS}

In this paper we have presented an econometric methodology for estimating the hidden economy, and have applied this methodology to New Zealand data. Our use of a structural MIMIC model, which treats the size of the hidden economy as a "latent" variable, is not novel in itself, but our coordination of this approach with a new currency demand model does distinguish our modelling methodology from others that have been used in this field. In addition, this study is the first such one to take proper account of the non-stationarity of the various economic time-series that are used in the estimation of the models.

We find that over the period 1968 to 1994, the New Zealand hidden economy averaged just under 9\% of measured GDP, varying between $6.8 \%$ in 1968 and $11.3 \%$ in 1994 . This ratio, and measured activity itself, were highly cyclical over this period, and these figures are consistent with the microeconomic evidence for New Zealand firms provided by Giles (1998a). The implied "tax-gap" ranged from $6.4 \%$ to $10.2 \%$ of total tax liability, or (equivalently) from $1.6 \%$ to $3.9 \%$ of GDP, in gross terms. Of course, only part of this tax-gap is recoverable in practice via fiscal means, and the results of Caragata and Giles (1998) and Giles and Caragata (1998) suggest that this amounts to about $50 \%$ of the total, on average over the cycle.

This same methodology can be applied to other countries, and recent such work for Canada by Tedds (1998) is being refined by her and the author. The availability of historical time-series data on the hidden economy provides new opportunities for empirical analyses of policy issues, with an explicit allowance for both measured and hidden sectors. For example, Giles (1998b) shows that the demand for money (M3) function in New Zealand is stable if its formulation allows for both hidden and recorded outputs. Johnson (1998) uses the data generated here to study money-income causality in New Zealand, and shows that allowing for the underground economy does not enhance the predictability of income from money. The results of these studies have important implications for monetary policy, but much more such work remains to be done if the policy implications of the underground economy in that and other countries are to be fully appreciated. 
TABLE 1

Outcomes of Unit Root Tests

Currency Demand Models: Quarterly Logarithmic Data

\begin{tabular}{lllll}
\hline Variable & & ADF Tests & & HEGY Tests \\
& I(3) vs. I(2) & I(2) vs. I(1) & I(1) vs. I(0) & \\
\hline CPI & Reject I(3) & I(2) & & SI(1) \\
CURR & Reject I(3) & I(2) & & SI(1) \\
GDP & Reject I(3) & Reject I(2) & I(1) & SI(1) \\
RBILL & Reject I(3) & Reject I(2) & I(1) & Zero \\
\hline
\end{tabular}

TABLE 2

ADF Tests for Unit Roots

MIMIC Models : Annual Levels Data

\begin{tabular}{llll}
\hline Variable & & ADF Tests & \\
& I(3) vs. I(2) & I(2) vs. I(1) & I(1) vs. I(0) \\
& & Reject I(2) & $\mathrm{I}(1)$ \\
\hline AATR & Reject I(3) & Reject I(2) & $\mathrm{I}(1)$ \\
AMTR & Reject I(3) & I(2) & \\
$\log ($ CPI) & Reject I(3) & Reject I(2) & $\mathrm{I}(1)$ \\
(CURR/M3) & Reject I(3) & Reject I(2) & $\mathrm{I}(1)$ \\
log(GDP) & Reject I(3) & Reject I(2) & $\mathrm{I}(1)$ \\
MPRT & Reject I(3) & Reject I(2) & $\mathrm{I}(0)$ \\
PUBEMP & Reject I(3) & Reject I(2) & $\mathrm{I}(0)$ \\
REGS & Reject I(3) & Reject I(2) & $\mathrm{I}(1)$ \\
RPDI & Reject I(3) & Reject I(2) & $\mathrm{I}(1)$ \\
TAXC & Reject I(3) & Reject I(2) & $\mathrm{I}(0)$ \\
TAXG & Reject I(3) & Reject I(2) & $\mathrm{I}(1)$ \\
TAXLEG & Reject I(3) & Reject I(2) & $\mathrm{I}(1)$ \\
TAXO & Reject I(3) & Reject I(2) & $\mathrm{I}(1)$ \\
UN & Reject I(3) & & \\
\hline
\end{tabular}


Table 3

Estimated Currency Demand Models

\begin{tabular}{|c|c|c|c|c|c|c|}
\hline $\begin{array}{l}\text { Coefficient } \\
\text { ("t value") }\end{array}$ & $\begin{array}{l}\text { Expected } \\
\text { Sign }\end{array}$ & Model 1 & Model 2 & Model 3 & Model 4 & Model 5 \\
\hline$\beta_{0}$ & $+/-$ & $\begin{array}{l}0.213 \\
(0.13)\end{array}$ & $\begin{array}{l}-0.578 \\
(-0.39)\end{array}$ & $\begin{array}{l}0.326 \\
(0.21)\end{array}$ & $\begin{array}{l}\text { n.a. } \\
\text { (n.a.) }\end{array}$ & $\begin{array}{l}1.044 \\
(0.69)\end{array}$ \\
\hline$\beta_{1}$ & + & $\begin{array}{l}0.035 \\
(0.08)\end{array}$ & $\begin{array}{l}0.244 \\
(1.34)\end{array}$ & $\begin{array}{l}0.007 \\
(0.03)\end{array}$ & $\begin{array}{l}0.128 \\
(0.35)\end{array}$ & $\begin{array}{l}0.034 \\
(0.18)\end{array}$ \\
\hline$\beta_{2}$ & + & $\begin{array}{l}0.276 \\
(0.61)\end{array}$ & $\begin{array}{l}0.141 \\
(3.72)\end{array}$ & $\begin{array}{l}0.302 \\
(10.43)\end{array}$ & $\begin{array}{l}0.222 \\
(0.41)\end{array}$ & $\begin{array}{l}0.128 \\
(8.47)\end{array}$ \\
\hline$\beta_{3}$ & - & $\begin{array}{l}-0.104 \\
(-3.89)\end{array}$ & $\begin{array}{l}-0.082 \\
(-3.70)\end{array}$ & $\begin{array}{l}-0.100 \\
(-4.62)\end{array}$ & $\begin{array}{l}-0.062 \\
(-2.40)\end{array}$ & $\begin{array}{l}-0.101 \\
(-4.56)\end{array}$ \\
\hline$\beta_{4}$ & + & $\begin{array}{l}0.729 \\
(18.11)\end{array}$ & $\begin{array}{l}0.694 \\
(19.26)\end{array}$ & $\begin{array}{l}0.724 \\
(19.26)\end{array}$ & $\begin{array}{l}0.680 \\
(19.73)\end{array}$ & $\begin{array}{l}0.746 \\
(19.23)\end{array}$ \\
\hline$\beta_{5}$ & $+/-$ & $\begin{array}{l}\text { n.a. } \\
\text { (n.a.) }\end{array}$ & $\begin{array}{l}-0.425 \\
(-0.64)\end{array}$ & $\begin{array}{l}0.732 \\
(1.14)\end{array}$ & $\begin{array}{l}-0.350 \\
(-1.69)\end{array}$ & $\begin{array}{l}1.272 \\
(2.23)\end{array}$ \\
\hline$\alpha_{1}$ & + & $\begin{array}{l}0.089 \\
(3.23)\end{array}$ & $\begin{array}{l}0.088 \\
(11.11)\end{array}$ & $\begin{array}{l}0.089 \\
(21.93)\end{array}$ & $\begin{array}{l}0.087 \\
(1.56)\end{array}$ & $\begin{array}{l}0.104 \\
(14.99)\end{array}$ \\
\hline$\alpha_{2}$ & - & $\begin{array}{l}-0.027 \\
(-0.85)\end{array}$ & $\begin{array}{l}-0.002 \\
(-0.08)\end{array}$ & $\begin{array}{l}-0.010 \\
(-0.90)\end{array}$ & $\begin{array}{l}-0.002 \\
(-0.16)\end{array}$ & $\begin{array}{l}-0.050 \\
(-5.52)\end{array}$ \\
\hline$\alpha_{3}$ & $+/-$ & $\begin{array}{l}-0.076 \\
(-0.82)\end{array}$ & $\begin{array}{l}\text { n.a. } \\
\text { (n.a.) }\end{array}$ & $\begin{array}{l}\text { n.a. } \\
\text { (n.a.) }\end{array}$ & $\begin{array}{l}\text { n.a. } \\
\text { (n.a.) }\end{array}$ & $\begin{array}{l}\text { n.a. } \\
\text { (n.a.) }\end{array}$ \\
\hline$\alpha_{4}$ & + & $\begin{array}{l}0.362 \\
(0.71)\end{array}$ & $\begin{array}{l}\text { n.a. } \\
\text { (n.a.) }\end{array}$ & $\begin{array}{l}\text { n.a. } \\
\text { (n.a.) }\end{array}$ & $\begin{array}{l}\text { n.a. } \\
\text { (n.a.) }\end{array}$ & $\begin{array}{l}\text { n.a. } \\
\text { (n.a.) }\end{array}$ \\
\hline$\alpha_{5}$ & + & $\begin{array}{l}0.044 \\
(0.26)\end{array}$ & $\begin{array}{l}\text { n.a. } \\
\text { (n.a.) }\end{array}$ & $\begin{array}{l}\text { n.a. } \\
\text { (n.a.) }\end{array}$ & $\begin{array}{l}\text { n.a. } \\
\text { (n.a.) }\end{array}$ & $\begin{array}{l}\text { n.a. } \\
\text { (n.a.) }\end{array}$ \\
\hline$\delta_{1}$ & $+/-$ & $\begin{array}{l}-0.102 \\
(-3.99)\end{array}$ & $\begin{array}{l}-0.135 \\
(-6.39)\end{array}$ & $\begin{array}{l}-0.117 \\
(-5.46)\end{array}$ & $\begin{array}{l}-0.126 \\
(-6.66)\end{array}$ & $\begin{array}{l}-0.084 \\
(-4.12)\end{array}$ \\
\hline$\delta_{2}$ & $+/-$ & $\begin{array}{l}-0.159 \\
(-4.62)\end{array}$ & $\begin{array}{l}-0.135 \\
(-8.15)\end{array}$ & $\begin{array}{l}-0.135 \\
(-8.06)\end{array}$ & $\begin{array}{l}-0.135 \\
(-8.28)\end{array}$ & $\begin{array}{l}-0.125 \\
(-5.38)\end{array}$ \\
\hline$\delta_{3}$ & $+/-$ & $\begin{array}{l}-0.157 \\
(-7.05)\end{array}$ & $\begin{array}{l}-0.140 \\
(-8.18)\end{array}$ & $\begin{array}{l}-0.144 \\
(-8.48)\end{array}$ & $\begin{array}{l}-0.142 \\
(-8.53)\end{array}$ & $\begin{array}{l}-0.143 \\
(-6.86)\end{array}$ \\
\hline$\delta_{4}$ & $+/-$ & $\begin{array}{l}\text { n.a. } \\
\text { (n.a.) }\end{array}$ & $\begin{array}{l}-0.098 \\
(-2.10)\end{array}$ & $\begin{array}{l}-0.061 \\
(-1.32)\end{array}$ & $\begin{array}{l}-0.089 \\
(-2.33)\end{array}$ & $\begin{array}{l}\text { n.a. } \\
\text { (n.a.) }\end{array}$ \\
\hline
\end{tabular}


Table 4

Diagnostic Tests for Currency Demand Model 1

\begin{tabular}{|c|c|c|c|c|}
\hline "Problem" & Test & Null Distribution & Statistic Value & p-Value \\
\hline \multirow[t]{2}{*}{ Non-Normality } & GOF & $\chi^{2}(3)$ & 1.292 & 0.731 \\
\hline & $\mathrm{JB}$ & $\chi^{2}(2)$ & 0.536 & 0.765 \\
\hline Omitted Variables/ & RESET2 & $\chi^{2}(1)$ & 12.927 & 0.000 \\
\hline Wrong Functional & RESET3 & $\chi^{2}(2)$ & 2.150 & 0.341 \\
\hline \multirow[t]{4}{*}{ Form } & RESET4 & $\chi^{2}(3)$ & 10.745 & 0.013 \\
\hline & FRESET2 & $\chi^{2}(4)$ & 0.314 & 0.990 \\
\hline & FRESET3 & $\chi^{2}(6)$ & 4.283 & 0.638 \\
\hline & FRESET4 & $\chi^{2}(8)$ & 5.051 & 0.752 \\
\hline \multirow[t]{4}{*}{ Autocorrelation } & LM1 & $\chi^{2}(1)$ & 2.606 & 0.106 \\
\hline & $\mathrm{LM} 2$ & $\chi^{2}(1)$ & 1.871 & 0.171 \\
\hline & LM3 & $\chi^{2}(1)$ & 0.871 & 0.351 \\
\hline & LM4 & $\chi^{2}(1)$ & 2.927 & 0.087 \\
\hline \multirow[t]{3}{*}{ Heteroskedasticity } & $\mathrm{H} 1$ & $\chi^{2}(1)$ & 2.479 & 0.115 \\
\hline & $\mathrm{H} 2$ & $\chi^{2}(1)$ & 2.463 & 0.117 \\
\hline & H3 & $\chi^{2}(1)$ & 2.491 & 0.115 \\
\hline
\end{tabular}


Table 5

MIMIC Model Results: Parameter Estimates

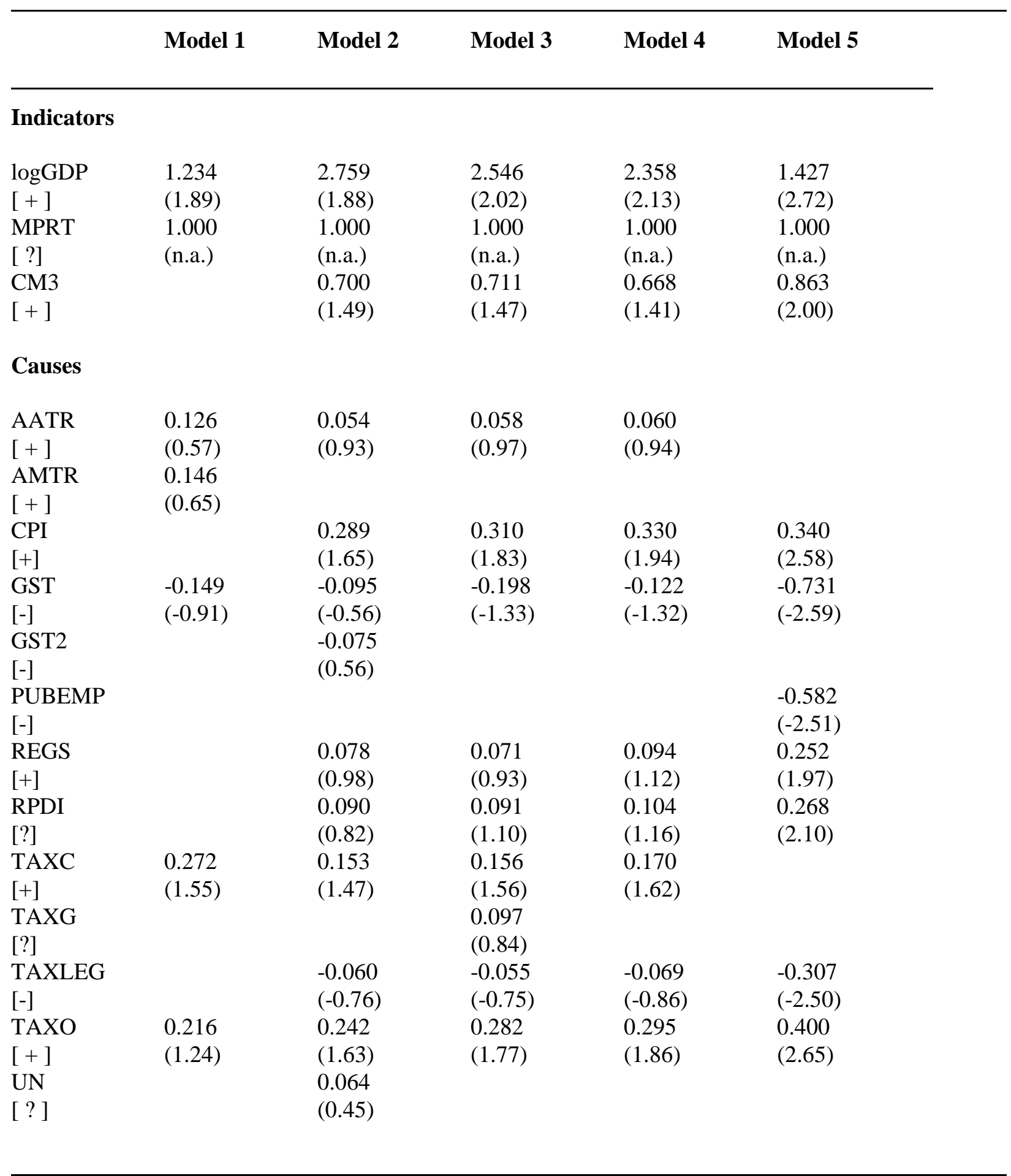

Notes: Anticipated signs appear in brackets.

Asymptotic "t-values" appear in parentheses below the estimated coefficients. 
Table 6

MIMIC Model Results: Goodness-of Fit

\begin{tabular}{|c|c|c|c|c|c|}
\hline & Model 1 & Model 2 & Model 3 & Model 4 & Model 5 \\
\hline \multicolumn{6}{|c|}{ Summary Statistics } \\
\hline Chi Square & 1.57 & 31.77 & 26.02 & 24.41 & 34.75 \\
\hline (n.c.p.; d.o.f.) & $(0 ; 4)$ & $(11.8 ; 20)$ & $(8.0 ; 18)$ & $(6.4 ; 16)$ & $(20.8 ; 14)$ \\
\hline [p-value] & {$[0.81]$} & {$[0.47]$} & {$[0.46]$} & {$[0.36]$} & {$[0.47]$} \\
\hline AIC & 49.57 & 173.77 & 146.02 & 122.41 & 116.75 \\
\hline CAIC & 103.77 & 334.10 & 281.51 & 235.32 & 209.33 \\
\hline ECVI & 1.98 & 6.95 & 5.84 & 4.90 & 4.67 \\
\hline AGFI & 0.88 & 0.43 & 0.48 & 0.52 & 0.31 \\
\hline PGFI & 0.14 & 0.19 & 0.20 & 0.21 & 0.21 \\
\hline RMR & 0.04 & 0.10 & 0.10 & 0.10 & 0.12 \\
\hline
\end{tabular}

Notes: $\quad$ n.c.p. $=$ non-centrality parameter; d.o.f. $=$ degrees of freedom.

Table 7

MIMIC Model 2 : Diagnostic Tests of "Conventional Residuals"

\begin{tabular}{lllllll}
\hline & GOF & JB & LM1 & LM2 & LM3 & LM4 \\
& & & & & \\
\hline CM3 & 3.047 & 0.469 & 0.679 & 0.112 & 0.353 & 0.221 \\
& $(0.38)$ & $(0.79)$ & $(0.41)$ & $(0.74)$ & $(0.55)$ & $(0.64)$ \\
$\operatorname{logGDP}$ & 3.047 & 0.476 & 0.729 & 0.096 & 0.349 & 0.243 \\
& $(0.38)$ & $(0.79)$ & $(0.39)$ & $(0.76)$ & $(0.55)$ & $(0.62)$ \\
MPRT & 3.047 & 0.508 & 0.741 & 0.090 & 0.374 & 0.239 \\
& $(0.38)$ & $(0.78)$ & $(0.39)$ & $(0.76)$ & $(0.54)$ & $(0.62)$ \\
\end{tabular}

Note: Asymptotic p-values appear in parentheses. 


\section{APPENDIX I}

DATA DEFINITIONS

Variable

AATR

AMTR

CM3

CPI

CURR

DEFT

GDP

GST

GST2

MPRT

M3

PUBEMP

RBILL

REGS

RPDI

TAXC

TAXG

TAXLEG

TAXO

TCOMP

TGST

TOTHER

UN
Definition

Average Average Tax Rate (\%)

Average Marginal Tax Rate (\%)

CURR/M3

Consumer's Price Index, All Groups (1993.4=1,000)

Currency (Notes and Coins) in Circulation (\$ Millions)

EFTPOS Transactions Dummy Variable

Real Gross Domestic Product (1982/1983 \$ Millions)

GST Introduction Dummy Variable

GST Increase Dummy Variable

Male Labour Force Participation Rate (\%/100)

Money Supply, M3 (\$ Millions)

Public Service Employees, Regulatory Depts. (Number)

90-Day Treasury Bill Rate (Quarterly Average, \% p.a.)

Index of Degree of Regulation of N.Z. Economy

Real Personal Disposable Income/Labour Force

[(TCOMP/CPI)/GDP]*10,000

[(TGST/CPI)/GDP]*10,000

Number of Sections in Income Tax Legislation

[(TOTHER/CPI)/GDP]*10,000

Gross Tax Revenue - Companies (\$ Millions)

Tax Revenue - Goods \& Services Tax (\$ Millions)

Gross Tax Revenue - Other Persons (\$ Millions)

Unemployment Rate (Total : Males + Females; \%)

\section{Source}

IRD

IRD

RBNZ

STATNZ

RBNZ

STATNZ

STATNZ

RBNZ

BERL

RBNZ

BERL

STATNZ

IRD; STATNZ

IRD; STATNZ

IRD; BERL

IRD; STATNZ

IRD

IRD

IRD

STATNZ

Note: $\quad B E R L=$ Data Constructed by Business and Economic Research Limited; IRD = Series Compiled from Official Data by Inland Revenue Department; RBNZ = Official Data Supplied by Reserve Bank of New Zealand; STATNZ = Oficfial Data Published by Statistics New Zealand 


\section{APPENDIX II}

An earlier version of this work formulated the currency demand model in the manner suggested by Bhattacharyya (1990) in his study of the hidden economy in the United Kingdom. As noted in section III above, our preferred cueency demand model is more flexible than that of Bhattacharyya, and it does not involve any functional approximations. However, as the application of several versions of his model to our data provides estimates of the long-run average ratio of hidden to measured output are almost identical to our $8.8 \%$, we present here a brief summary of these earlier results.

Demand for currency comprises two parts - that for recorded activity and that for hidden activity:

$$
\mathrm{M}_{\mathrm{t}}=\mathrm{M}_{\mathrm{Rt}}+\mathrm{M}_{\mathrm{Ht}}
$$

where, with lower case symbols (in our earlier notation) denoting natural logarithms,

$$
\begin{aligned}
& \mathrm{m}_{\mathrm{Rt}}=\log \alpha_{0+} \beta_{1} \mathrm{y}_{\mathrm{Rt}}+\beta_{2} \mathrm{r}_{\mathrm{t}}+\beta_{3} \mathrm{p}_{\mathrm{t}}+\epsilon_{\mathrm{t}} \\
& \mathrm{m}_{\mathrm{Ht}}=\beta_{4} \mathrm{y}_{\mathrm{Ht}} .
\end{aligned}
$$

Combining these equations, taking a first-order Taylor series approximation, and using the proxy:

$$
\mathrm{Y}_{\mathrm{Ht}}=\alpha_{1} \mathrm{Y}_{\mathrm{Rt}}+\alpha_{2} \mathrm{Y}_{\mathrm{Rt}}{ }^{2}+\alpha_{3} \mathrm{Y}_{\mathrm{Rt}}{ }^{3}+\alpha_{4} \mathrm{Y}_{\mathrm{Rt}}{ }^{4}+\ldots \ldots \ldots+\alpha_{\mathrm{n}} \mathrm{Y}_{\mathrm{Rt}}{ }^{\mathrm{n}}+\omega_{\mathrm{t}}
$$

we get the non-linear estimating equation (which includes the EFTPOS dummy variable):

$$
\mathrm{m}_{\mathrm{t}}=\log \alpha_{0}+\delta_{1} \mathrm{DEFT}_{\mathrm{t}}+\beta_{1} \mathrm{y}_{\mathrm{Rt}}+\beta_{2} \mathrm{r}_{\mathrm{t}}+\beta_{3} \mathrm{p}_{\mathrm{t}}+\left[\left(\alpha_{1} \mathrm{Y}_{\mathrm{Rt}}\right)_{4}{ }_{4} /\left(\alpha_{0} \mathrm{Y}_{\mathrm{Rt}}{ }_{1} \mathrm{R}_{\mathrm{t}}{ }_{2} \mathrm{P}^{\beta}{ }_{3}\right)\right]+\text { error },
$$

where we have taken $n=1$, so that $\alpha_{1}$ is the long-run average ratio of $\mathrm{Y}_{\mathrm{Ht}}$ to $\mathrm{Y}_{\mathrm{Rt}}$. Allowing for an $\mathrm{AR}(1)$ process in the error, with autocorelation parameter $\rho$, we obtain the following results (with the diagnostic tests defined as in Table 4 above):

$\begin{array}{lllllll} & \alpha_{0} & \alpha_{1} & \beta_{1} & \beta_{2} & \beta_{3} & \beta_{4} \\ \text { Estimate } & 1.160 & 0.086 & 0.711 & -0.100 & 0.731 & -34.647 \\ \text { "t-value" } & (2.443) & (20.143) & (8.287) & (-3.285) & (21.418) & (-19.406) \\ & \delta_{1} & \rho & & & \\ \text { Estimate } & -0.108 & -0.009 & & & \\ \text { "t-value" } & (-2.981) & (-0.079) & & & \\ \mathrm{R}^{2}=0.982 ; & \mathrm{LM} 1=0.016 ; \mathrm{LM} 2=0.668 ; \mathrm{JB}=10.262 ; & \mathrm{GOF}=11.975 \\ & {\left[\chi^{2}(1)\right]} & {\left[\chi^{2}(1)\right]} & {\left[\chi^{2}(2)\right]} & {\left[\chi^{2}(3)\right]}\end{array}$




\section{REFERENCES}

Aigner D J, Schneider F and Ghosh D (1988) Me and my shadow: estimating the size of the hidden economy from time series data. In Barnett, W. A. et al. (eds), Dynamic econometric modeling: proceedings of the third international symposium in economic theory and econometrics, Cambridge University Press, Cambridge pp 297-334

Akaike H. (1974) A new look at statistical model identification. IEEE Transactions on Automatic Control 19: 716-723

Bhattacharyya D K (1990) An econometric method of estimating the 'hidden economy', United Kingdom (1960-1984) : estimates and tests. Economic Journal 100: 703-717

Blades D (1982) The hidden economy and the national accounts. OECD, Paris

Boeschoten W C, Fase M M G (1984) The volume of payments and the informal economy in the Netherlands, 1965-1982. Nijhoff, Dordrecht

Bozdogan H (1987) Model selection and Akaike's information criteria (AIC). Pychometrika 52: 345-370

Caragata P J, Giles D E A (1998) Simulating the relationship between the hidden economy and the tax mix in New Zealand. Econometrics Working Paper EWP9804, Department of Economics, University of Victoria

Carter M (1984) Issues in the hidden economy - a survey. Economic Record 60: 209-221

Chote R (1995) 'Black economy' believed to exceed \$100bn. Financial Times, 10-11 June.

DeBenedictis L F, Giles D E A (1998) Testing the specification of regression models using Fourier series approximations: the FRESET test. In Ullah A and Giles D E A (eds) Handbook of applied economic statistics, Marcel Dekker, New York pp 383-417

Dickey D A, Pantula S G (1987) Determining the order of differencing in autoregressive processes. Journal of Business and Economic Statistics 15: 455-461

Dods J L, Giles, D E A (1995) Alternative strategies for 'augmenting' the Dickey-Fuller test: sizerobustness in the face of pre-testing. Journal of Statistical Computation and Simulation 53: 243-258

Dolado J J, Jenkinson T, Sosvilla-Rivero S (1990) Cointegration and unit roots'. Journal of Economic Surveys 4: 249-273 
Feige E L (1982) A new perspective on macroeconomic phenomena: the theory and measurement of the unobserved economy in the United States: causes, consequences and implications. In Walker M (ed) International burden of government, The Fraser Institute Vancouver pp $112-136$

Frey B S, Pommerehne W W (1982) Measuring the hidden economy: though there be madness, yet is there method in it?. In Tanzi V (ed) The underground economy in the United States and abroad, Heath Lexington pp 3-27

Frey B S, Pommerehne W W (1984) The hidden economy: state and prospects for measurement. Review of Income and Wealth 30: 1-23.

Frey B S, Weck-Hannemann H (1984) The hidden economy as an 'unobserved' variable. European Economic Review 26: 33-53

Gaertner W, Wenig A eds (1985) The economics of the shadow economy, Springer-Verlag Heidelberg

Ghysels E, Lee H S, Noh J (1994) Testing for unit roots in seasonal time series. Journal of Econometrics 62: 415-442

Giles D E A (1995) Measuring the size of the hidden economy and the tax-gap in New Zealand: an econometric analysis. Working Paper No. 5a, Working Papers on Monitoring the Health of the Tax System, Inland Revenue Department, Wellington.

Giles D E A (1997a) The hidden economy and the tax-gap in New Zealand: a latent variable analysis. Discussion Paper 97-8, Department of Economics, University of Victoria.

Giles D E A (1997b) Causality between the measured and underground economies in New Zealand. Applied Economics Letters 4: 63-67

Giles D E A (1997c) The hidden economy and tax-evasion prosecutions in New Zealand. Applied Economics Letters 4: 281-285

Giles D E A (1997d) Testing for asymmetry in the measured and underground business cycles in New Zealand. Economic Record 72: 225-232

Giles D E A (1998a) Modelling the tax compliance profiles of New Zealand firms: evidence from audit records. Econometrics Working Paper EWP9803, Department of Economics, University of Victoria 
Giles D E A (1998b) Measuring the hidden economy: implications for econometric modelling. Econometrics Working Paper EWP9809, Department of Economics, University of Victoria

Giles D E A (1999) The rise and fall of the New Zealand underground economy: are the responses symmetric?.Forthcoming in Applied Economic Letters

Giles D E A, Caragata P J (1998) The learning path of the hidden economy: tax and growth effects in New Zealand. Econometrics Working Paper EWP9805, Department of Economics, University of Victoria

Goldberger A S (1972) Structural equation methods in the social sciences, North-Holland Amstterdam

Granger C W J, Newbold P (1974) Spurious regressions in econometrics. Journal of Econometrics 35: $143-159$

Haldrup N (1994) The asymptotics of single-equation cointegration regressions with I(1) and $\mathrm{I}(2)$ variables. Journal of Econometrics 63: 153-181

Hylleberg S, Engle R F, Granger C W J, Yoo B S (1990) Seasonal integration and co-integration. Journal of Econometrics 44: 215-28

Internal Revenue Service (1996) Individual income tax gap estimates for 1985, 1988 and 1992. Publication 1415 (Rev. 4-96), Doc. 96-13553, Research Division, Internal Revenue Service, Washington, D.C.

Jarque C M, Bera A K (1980) Efficient tests for normality, homoscedasticity and serial independence of regression residuals. Economics Letters 6: 255-259

Johnson B J J (1988) Money-income causality and the New Zealand underground economy. Unpublished M.A. Extended Essay, Department of Economics, University of Victoria

Jöreskog K, Goldberger A S (1975) Estimation of a model with multiple indicators and multiple causes of a single latent variable. Journal of the American Statistical Association 70: 631-639

Jöreskog K, Sörbom D (1993a) LISREL 8: structural equation modeling with the SIMPLIS command language, Scientific Software International Chicago

Jöreskog K, Sörbom D (1993b) LISREL 8 user's reference guide, Scientific Software International Chicago

Kirchgaessner G (1984) Verfahren zur erfassung des in der schattenwirtschaft erabeiteten sozial produkts. Allegemeines Statistisches Archiv 68: 378-405 
Mirus R, Smith R S (1994) Canada's underground economy revisited: update and critique. Canadian Public Policy 20: 235-252

Park T (1979) Reconciliation between personal income and taxable income, 1947-1977. Mimeo., Bureau of Economic Analysis, Washington, D. C.

Perron P (1989) The great crash, the oil price shock, and the unit root hypothesis. Econometrica 57: 1361-1401

Ramsey J B (1969) Tests for specification errors in classical linear least-squares regression analysis. Journal of the Royal Statistical Society B 31: 350-371

Said S E, Dickey D A (1984) Testing for unit roots in autoregressive-moving average models of unknown order. Biometrika 71: 599-607

Schneider F (1997) Empirical results for the size of the shadow economy of Western European countries over time. Working Paper 9710, Instutut Für Volkswirtschaftslehre, Linz University

Schneider F, Pommerehne W W (1985) The decline of productivity growth and the rise of the shadow economy in the U. S.. Mimeo., University of Århus

SHAZAM (1993) SHAZAM econometrics computer program: user's reference manual, version 7.0, McGraw-Hill New York

Spiro P S (1994) Evidence of a post-GST increase in the underground economy. Canadian Tax Journal 41: 247-258

Tanzi V (1983) The underground economy in the United States: annual estimates, 1930-1980. IMF Staff Papers 30: 283-305

Tedds L M (1998) Measuring the size of the hidden economy in Canada: a latent variable/MIMIC model approach. Unpublished M.A. Extended Essay, Department of Economics, University of Victoria

Weck H (1983) Schattenwirtschaft: eine möglichkeit zur einschränkung der öffentlichen verwaltung?, Peter Lang Verlag Bern

Zellner A (1970) Estimation of regression relationships containing unobservable variables. International Economic Review 11: 441-454 
Figure 1 : MIMIC Model 2

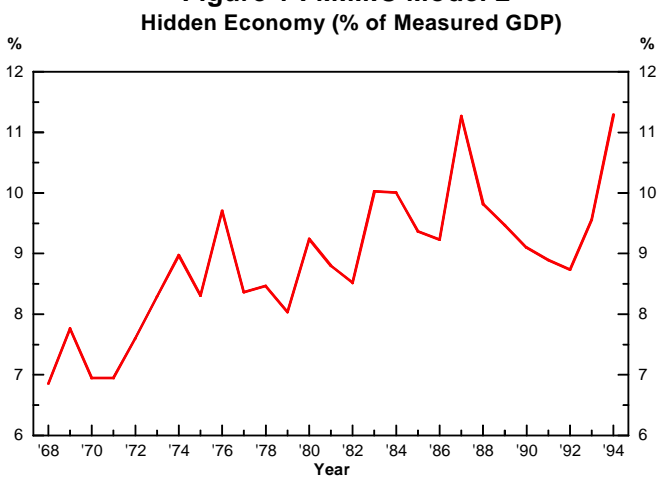

Figure 2: Measured and Hidden GDP (Real 1982/1983 \$ Millions)

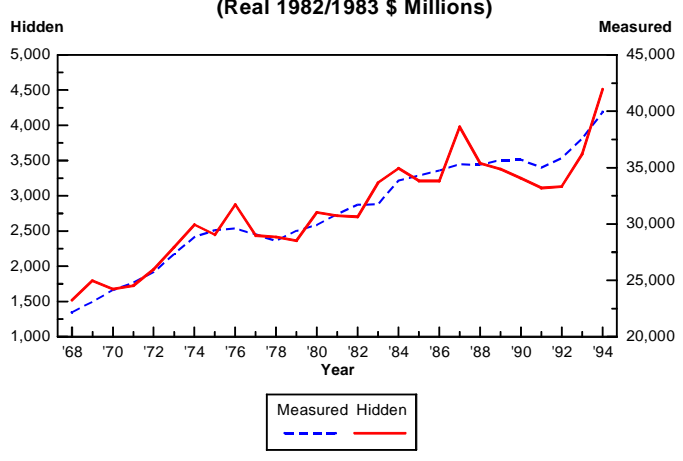

Figure 3: Tax-Gap

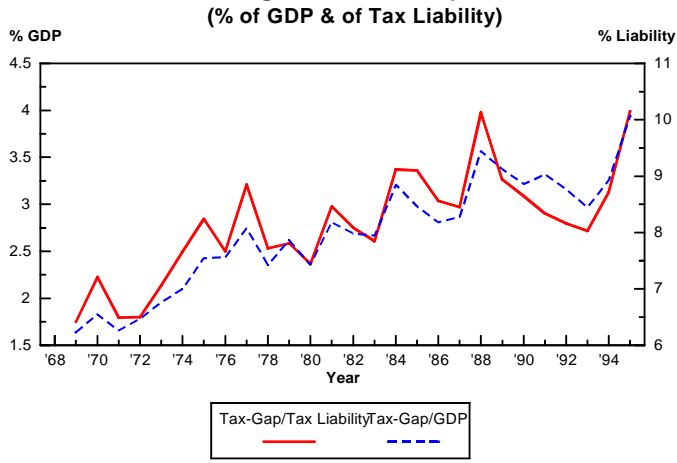

